\title{
OFICINA DE LIVRO TÁTIL: UMA PROPOSTA DE CAPACITAÇÃO DE PROFESSORES POR MEIO DO ENSINO REMOTO DURANTE A PANDEMIA
}

\author{
TACTILE BOOK WORKSHOP: A PROPOSAL FOR TEACHER TRAINING \\ THROUGH REMOTE TEACHING DURING THE PANDEMIC
}

\author{
Lisânia Cardoso Tederixe ${ }^{1}$ \\ Cristina Silva Ribeiro de Souza ${ }^{2}$
}

RESUMO: O artigo tem como objetivo mostrar a possibilidade de uma capacitação profissional no formato de ensino remoto emergencial, no período de pandemia, para profissionais que trabalham ou que pretendam trabalhar na área de deficiência visual. Foi ofertada uma oficina sobre livro tátil com is vagas, por meio da Divisão de Extensão e Aperfeiçoamento do Instituto Benjamin Constant, com o intuito de apresentar e discutir conceitos e técnicas de produção do livro tátil artesanal. Assim também, foi proposto a confecção de parte de um livro tátil para as cursistas e uma avaliação, através do Google formulário, sobre o conteúdo da temática do livro tátil e o formato utilizado para a realização da oficina.

Palavras- chave: Livro Tátil. Ensino Remoto. Capacitação. Pandemia.

ABSTRACT: The article aims to show the possibility of professional training in the format of emergency remote education, during the pandemic period, for professionals who work or intend to work in the field of visual impairment. A workshop on tactile books with is places was offered through the Benjamin Constant Institute by the Extension and

\footnotetext{
1 Mestra em Diversidade e Inclusão pela Universidade Federal Fluminense- UFF/ 2019. Especialista em Educação Especial e Inclusiva pela Universidade Cândido Mendes / AVM). Aperfeiçoamento na área de Deficiência Visual pelo Instituto Superior de Educação do Estado do Rio de Janeiro. Graduada e licenciada em Letras: Português- árabe pela Universidade Federal do Rio de Janeiro. Possui experiência em deficiência visual e surdez. Professora do Ensino Técnico e Tecnológico do Instituto Benjamin Constant.(IBC) https://orcid.org/oooo-ooor-8o58-2845.E-mail: lisaniac@bol.com.br.

${ }_{2}$ Mestra em Diversidade e Inclusão pela Universidade Federal Fluminense - UFF/2019. Especialista em Psicomotricidade pela Universidade Cândido Mendes (AVM); graduada em Pedagogia, com habilitação em supervisão escolar pelo Instituto Isabel Faculdade de Ciências Humanas e Sociais; formada em magistério de nível médio (antigo normal) pelo Curso de Formação de Professores do Instituto de Educação do Rio de Janeiro e C.E. Júlia Kubtschek. Professora do Ensino Técnico e Tecnológico do Instituto Benjamin Constant. (IBC) E-mail: crisaquilis@gmail.com.
} 
Improvement Division, with the aim of presenting and discussing concepts and techniques for the production of handcrafted tactile books. Likewise, the preparation of part of a tactile book was proposed for the course participants and an evaluation, through Google form, on the content of the tactile book theme and the format used to carry out the workshop.

Keywords: Tactile Book. Remote Learning. Training. Pandemic.

\section{INTRODUÇÃO}

Durante o período de distanciamento social, causado pela pandemia do COVID- I9, os professores perceberam que a formação continuada passou a ser um fator essencial para se atualizar em novas práticas pedagógicas e ao mesmo tempo se apoiar nas tecnologias digitais para adaptar as suas aulas presenciais em on-line. De acordo com o capítulo II da política da formação continuada de professores:

Art. $4^{\circ}$ A Formação Continuada de Professores da Educação Básica é entendida
como componente essencial da sua profissionalização, na condição de agentes
formativos de conhecimentos e culturas, bem como orientadores de seus
educandos nas trilhas da aprendizagem, para a constituição de competências,
visando o complexo desempenho da sua prática social e da qualificação para o
trabalho." (MEC, 2020)

Há algum tempo, os cursos no formato a distância têm ganho foco e se mostrado aliados na formação continuada, esses cursos tornaram-se atrativos por serem mais baratos que os presenciais e ou gratuitos, como também, pela flexibilidade de horários. Há cursos que são transmitidos ao vivo ou gravados. A possibilidade de estudar no seu tempo é uma proposta tentadora, principalmente, para os profissionais de educação que tem um tempo escasso, devido a muitas horas laborais. Segundo Tederixe e Lima (2020), a nova realidade escolar mostra a presença de um público heterogêneo dentro da sala de aula ao nos deparamos por alunos com diferentes necessidades específicas como: a deficiência visual, auditiva, física e intelectual. Seguindo na direção da inclusão, a formação continuada de professores sempre foi o melhor caminho para preparar profissionais e termos um melhor resultado no atendimento desses educandos no ensino regular. Sendo assim, os formatos de ensino a distância ou remoto emergencial foram 


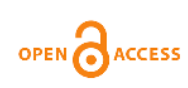

propiciados para atender as demandas da educação em tempos de pandemia. "O ensino remoto permite o uso de plataformas já disponíveis e abertas para outros fins, que não sejam estritamente os educacionais, assim como a inserção de ferramentas auxiliares e a introdução de práticas inovadoras" (GARCIA et al, p.5, 2020).

\footnotetext{
“O ensino remoto emergencial é uma mudança temporária na forma de ensinar, utilizando uma modalidade alternativa de transmissão de conhecimento devido a circunstâncias críticas. Enquanto o ensino a distância eficiente visa instruir os alunos por meio de engajamento co-curricular e outros apoios sociais."(HODGES et al, p. 95-96, 2020).
}

As tecnologias digitais tornaram-se fortes ferramentas para que o professor se reinvente e desenvolva novas metodologias e amplie as suas práticas pedagógicas, tanto na posição de cursista assimilador de novos conhecimentos quanto na função de gerador de conhecimento e informação aos seus educandos.

O objetivo deste artigo é mostrar como o ensino remoto emergencial passou a ser uma alternativa plausível na formação continuada de profissionais que já trabalham ou pretendem trabalhar no ensino de pessoas com deficiência visual por intermédio de uma oficina de livro tátil ofertada pelos cursos e oficinas na área de deficiência visual no formato remoto do Instituto Benjamin Constant (IBC). Com isso, a proposta da oficina de livro tátil surgiu por parte de duas professoras do IBC em parceria com a Divisão de Extensão e Aperfeiçoamento (DEA) com base em pesquisas de livros acessíveis para pessoas com deficiência visual e suas vivências práticas na produção e eficiência do livro tátil. A finalidade da oficina era mostrar aos cursistas os procedimentos das técnicas de produção do livro tátil artesanal direcionado ao ensino de crianças com deficiência visual, assim utilizando materiais acessíveis e ou de baixo custo. E que os cursistas pudessem elaborar parte de um livro tátil.

O Instituto é um centro de referência no ensino e pesquisa na área de deficiência visual que oferece, anualmente, cursos e oficinas presenciais e desde o ano de 2017 também vem ofertando cursos no formato a distância. Os primeiros cursos promovidos pela 
Coordenação de Educação a Distância (CEAD) foram alfabetização no Sistema Braille e Programa de informática na área de deficiência visual. Hoje, a CEAD abarca vários cursos e oficinas na área de tecnologias digitais. No primeiro semestre do ano de 202I, o Instituto passou a ofertar também no formato de ensino remoto pela DEA, alguns cursos e oficinas de formação continuada que já existiam presencialmente, sendo esse um meio para dar prosseguimento aos cursos e oficinas de extensão e aperfeiçoamento na área de deficiência visual no período de pandemia.

\section{I- LIVVRO TÁTIL}

Livros táteis são livros utilizáveis por todo pequeno leitor, mas considerando a criança com deficiência visual (cego ou com baixa visão), os livros táteis produzidos necessitam de algumas características específicas no que diz respeito às ilustrações criadas, tais como materiais com diferentes texturas, textos escritos em Braille e letras ampliadas (PICCARDI, 20II).

Em todo o processo criativo de um livro tátil é fundamental pensar na contribuição em que ele irá proporcionar, como por exemplo, um diálogo facilitador entre o texto, a imagem e o pequeno leitor com deficiência visual (DV). Romani explica que as imagens no livro podem ter o mesmo valor que na memória visual como processo associativo, pois a imagem mental não deriva apenas da visão. E sobre a criança cega, a imagem tátil precisa ser trabalhada e contextualizada para que seja possível o reconhecimento do desenho a partir daquilo que ela internalizou (ROMANI, 2016). Neste contexto é importante ressaltar o quanto se faz relevante proporcionar estímulos táteis nos livros de histórias infantis, pois assim a criança terá muito mais possibilidade de construir e memorizar conceitos que são apresentados a partir das narrativas (SOUZA, 2019).

As ilustrações inicialmente possibilitam que a criança, mesmo ainda não alfabetizada, realize uma leitura imaginativa, criativa e espontânea. Cardeal (2019, p.16) explica que "a ilustração cria um novo texto, abrindo possibilidade para uma terceira 


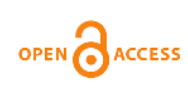

leitura, dinamizando as relações entre palavra, imagem, e a imaginação do leitor.” Efetivamente, a ilustração de um livro tátil representa para a criança a magnitude, pois é um meio atenuante no que diz respeito à compreensão da narrativa, ainda que esta não tenha domínio de leitura e escrita. Nessa perspectiva Aride reitera que,

\begin{abstract}
"Ainda que não se encontrem familiarizadas com o texto verbal, por meio das ilustrações, os infantes mais novos conseguem identificar pequenas situações e compreender o conteúdo narrado. O livro ilustrado, desse modo, fornece respaldo à história, e promove a associação entre texto e imagem de forma lúdica, possibilitando uma melhor compreensão da narrativa e ampliando o repertório e conhecimentos pessoais." (ARIDE, 2015 p.33)
\end{abstract}

Para que as narrativas infantis de um livro ilustrado tátil promovam uma melhor compreensão para a criança, é importante que elementos bidimensionais e/ou tridimensionais sejam utilizados na composição das imagens, pois estes funcionarão como elementos facilitadores e ferramentas consideradas peculiares para o entendimento do texto.

Nuernberg (2010) afirma que é preciso garantir a acessibilidade do conteúdo visual dos livros infantis para as crianças cegas através de ilustrações táteis. O mesmo autor ainda ressalta que a experiência da criança em relação a tudo que está ao seu redor é majoritariamente tridimensional. Souza (2019) define que livro tátil tridimensional é o efeito de adaptar algo de forma palpável e em três dimensões em que, a partir deste formato, a criança cega poderá tatear e interpretar as imagens que estão nos livros e construir tais conhecimentos que lhe são apresentados. Nuernberg (2010) ainda complementa que o papel das imagens nos livros é o de justamente possibilitar a compreensão e o envolvimento da criança na narrativa, onde se espera que as adaptações táteis cumpram o mesmo objetivo de igualdade.

Devemos considerar que nem todas as adaptações de imagens visuais para táteis possam ser eficientes, ou seja, representam uma legibilidade tátil suficiente para a compreensão de uma leitura tátil/háptica. Nem todo livro tátil é feito para pessoas com 
deficiência visual (TEDERIXE; LIMA, 2018). Para tanto, é preciso considerar alguns critérios na construção de livros táteis infantis.

Figura 1: Fluxograma dos critérios de construção de livros táteis

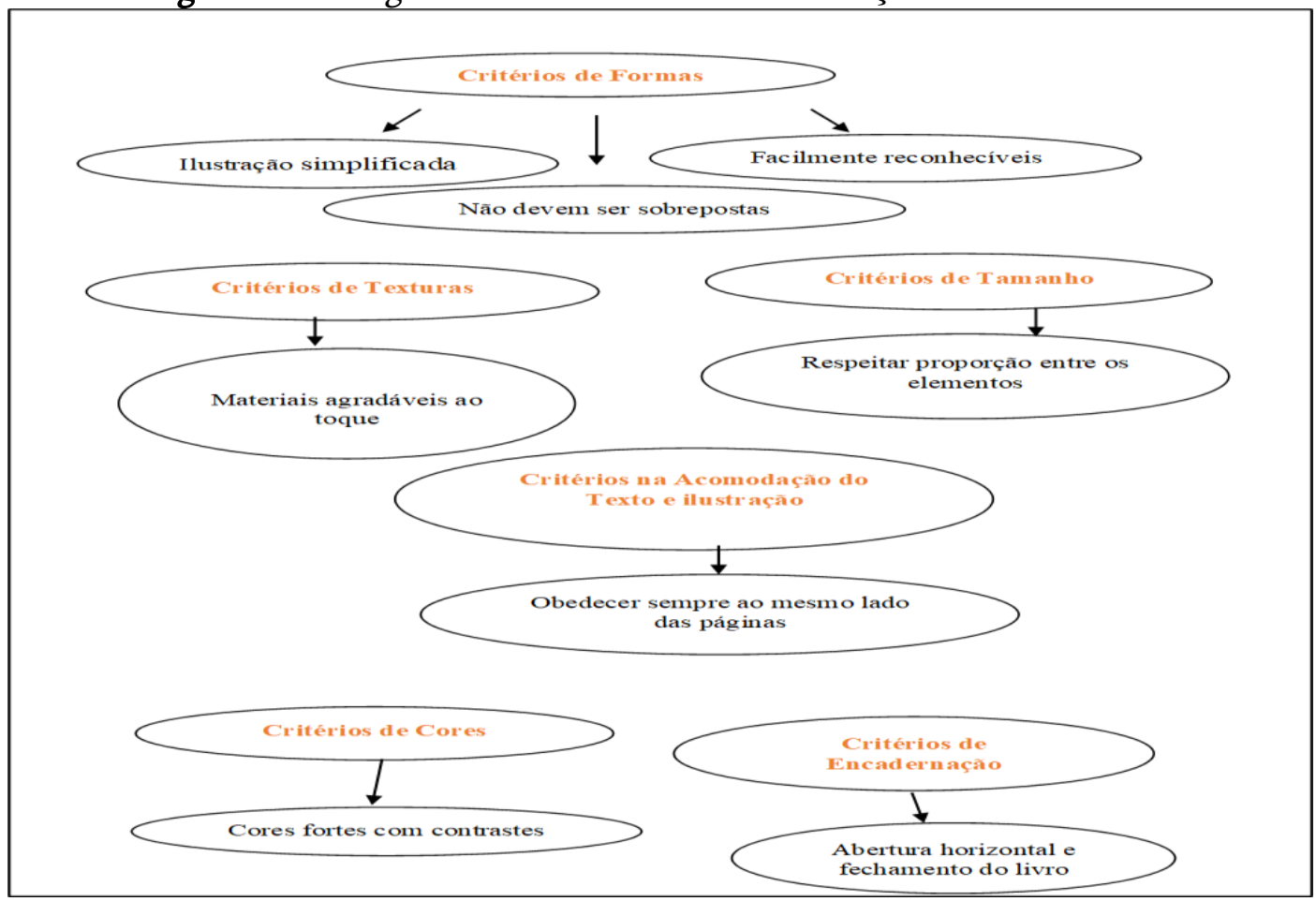

Fonte: Elaborado pelas autoras

\section{2- M ETODOLOGIA}

A pesquisa é de caráter quali/quantitativo com base na coleta de dados feito por meio do Google formulário com perguntas semiestruturadas abertas e fechadas. Tivemos a participação de 15 cursistas inscritos na oficina de livro tátil em maio de 202I, sendo esse o número de vagas previstas. As aulas foram realizadas no formato remoto com 8 aulas síncronas pelo Google Meet e 4 assíncronas pelo Google sala de aula. Por ser uma oficina, teríamos que ter uma proposta prática para os cursistas desenvolverem, assim também tivemos que ofertar conteúdo teórico para que tivessem base sobre o assunto do livro tátil, tais como: conceito do livro tátil, tipologias do livro tátil e técnicas para a construção do 
livro. Nas atividades assíncronas foram postados textos complementares para estudo dos cursistas sobre o tema. A proposta final da oficina foi a construção de parte de um livro tátil. O participante da oficina poderia apresentar um protótipo desse livro, no qual contivesse: público-alvo, tema/ área, ilustração tátil bidimensional/ tridimensional e tipos de textura.

\section{4-RESULTADOS E DISCUSSÕES}

Foram realizadas 14 perguntas que se distribuíram em três partes: identificar o perfil desse cursista que se propôs a fazer uma oficina com uma temática muito específica de livros acessíveis. Saber sobre o conhecimento prévio e adquirido por meio da oficina sobre o livro tátil e a eficiência do método utilizado para o desenvolvimento da oficina no formato remoto. Sendo uma oficina remota, há a possibilidade de pessoas de vários locais do Brasil. No total de 15 participante, apenas 14 responderam ao questionário.

Quadro I: Perfil das pessoas que procuraram a oficina do livro tátil

\begin{tabular}{|l|l|}
\hline Região & Norte: (AM), Nordeste: (BA,PE), Sudeste: (RJ, SP), Sul: (PR) \\
\hline Faixa etária & 25 a 59 anos \\
\hline Gênero & Feminino \\
\hline Profissão & Filosofia, Pedagogia, Geóloga, Artes, Letras. Especialização em Ed. Especial \\
\hline Trabalham com DV & II \\
\hline $\begin{array}{l}\text { Conhecimento de } \\
\text { Braille }\end{array}$ & II \\
\hline
\end{tabular}

Fonte: Elaborado pelas autoras

Dentre os 15 primeiros cursistas inscritos contemplados para participar da oficina, observamos uma hegemonia do gênero feminino, embora não podemos dizer que seja completamente a predominância dessa procura, porque havia outras pessoas na fila de espera. Por ser uma oficina no formato remoto, então tivemos cursistas de quatro regiões do Brasil: norte, nordeste, sul e sudeste.

Os próximos seis gráficos têm como proposta saber a percepção das cursistas sobre a funcionalidade do livro tátil como mais um método de ensino e aprendizado da pessoa 
com deficiência visual a partir do conteúdo apresentado na oficina e a possibilidade de inserir o livro tátil artesanal como uma prática de ensino no ambiente escolar.

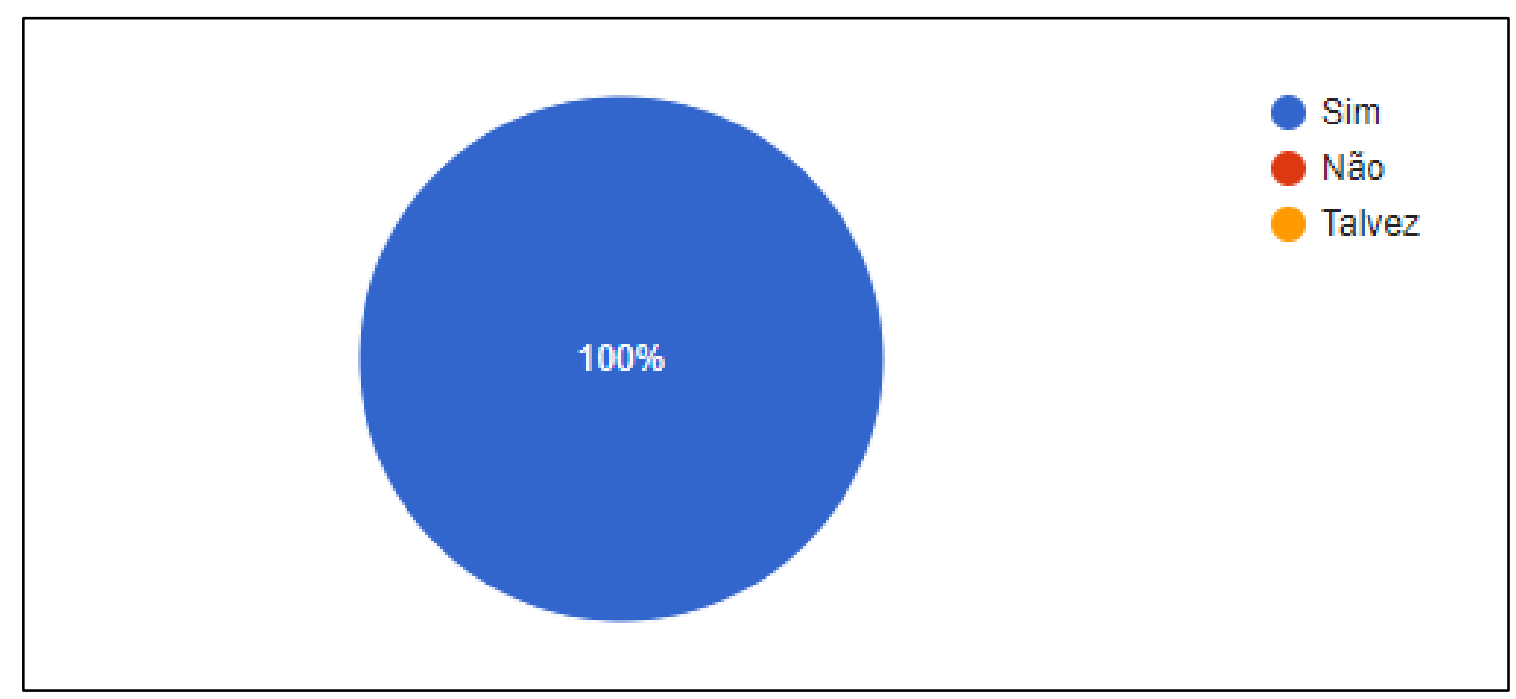

Gráfico r: O livro tátil seria um bom recurso para trabalhar conceitos com os alunos com DV

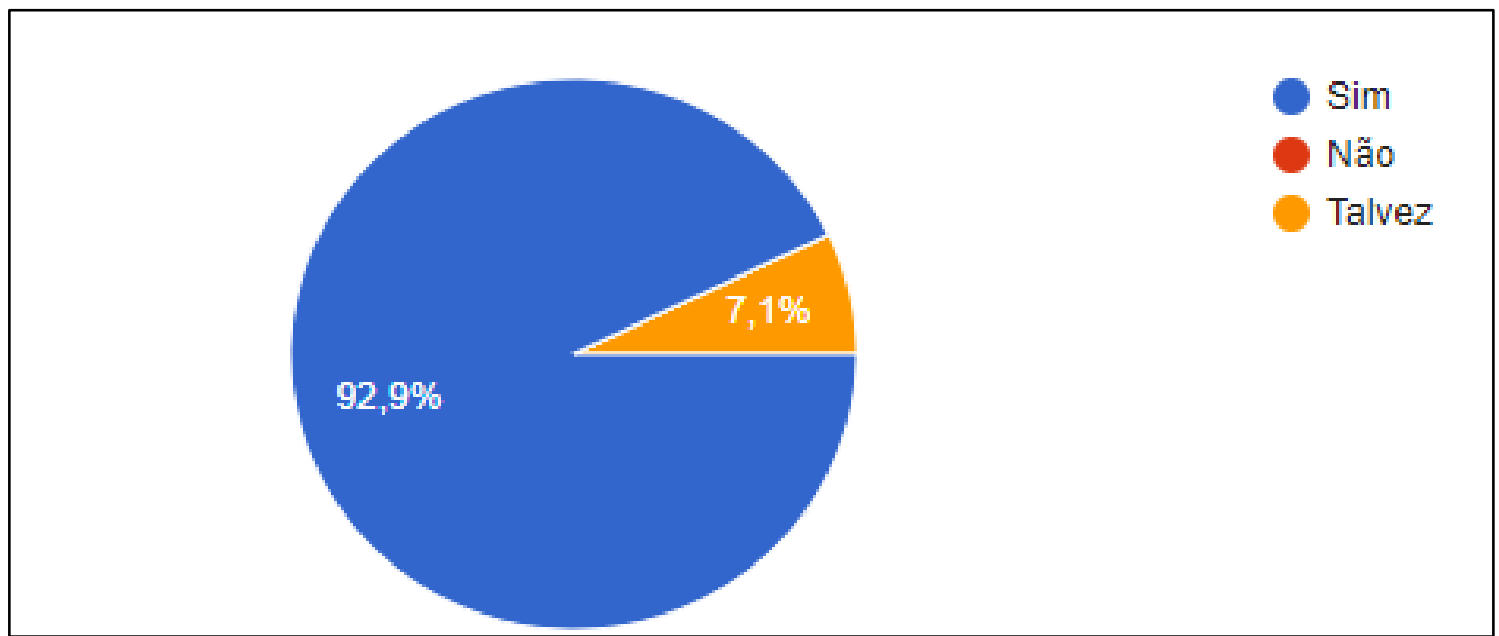

Gráfico 2: Você desenvolveria um livro artesanal, caso tenha ou tivesse um aluno com deficiência visual

Nos gráficos 3,4 e 5 destacam os critérios elencados ao livro tátil artesanal quanto a ser um livro inclusivo ao tornar acessível as ilustrações visuais em táteis, como também, ser um material que tanto pessoas com ou sem deficiência possam utilizar nas diversas 
áreas do saber. Além de poder trabalhar a ludicidade por meio de histórias que serão narradas por textos em Braille ou imagens táteis.

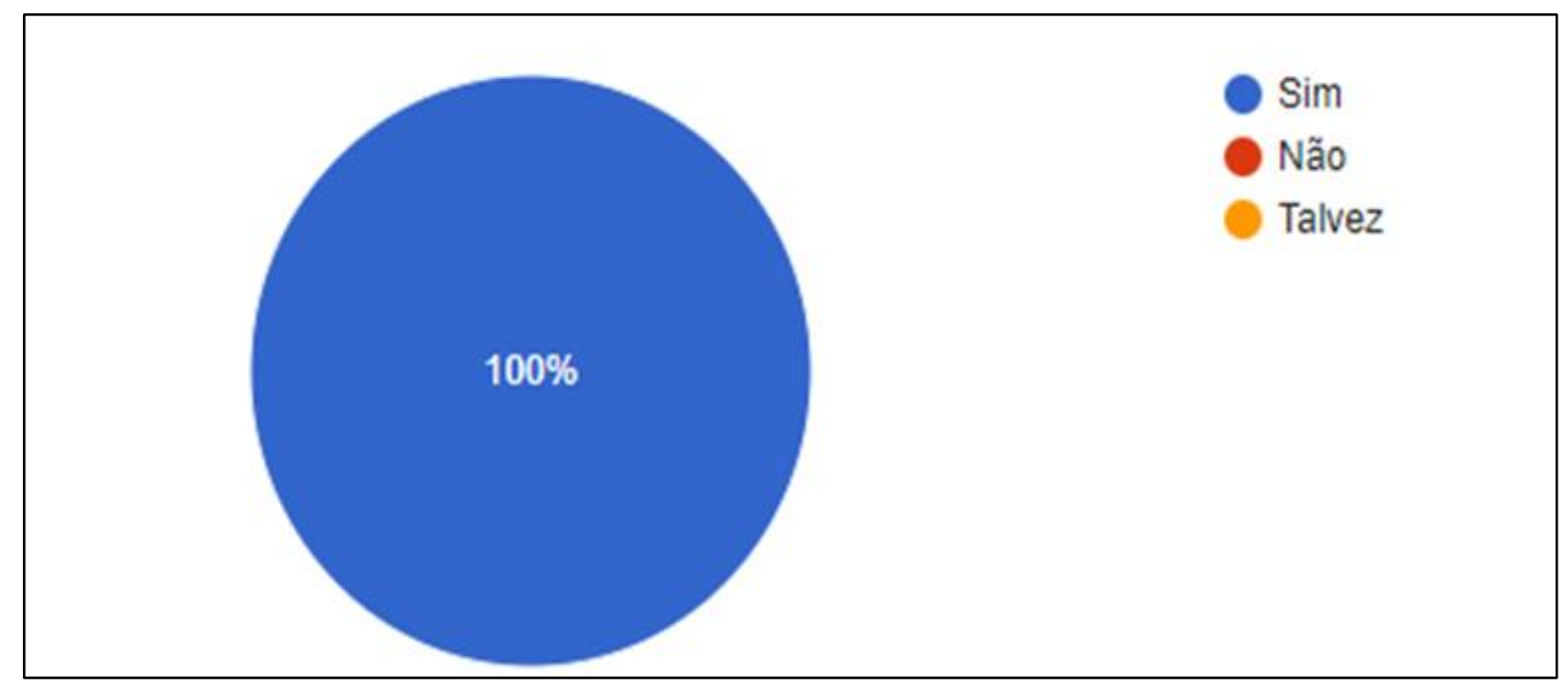

Gráfico 3: O livro tátil artesanal é um livro inclusivo para alunos com o sem deficiência

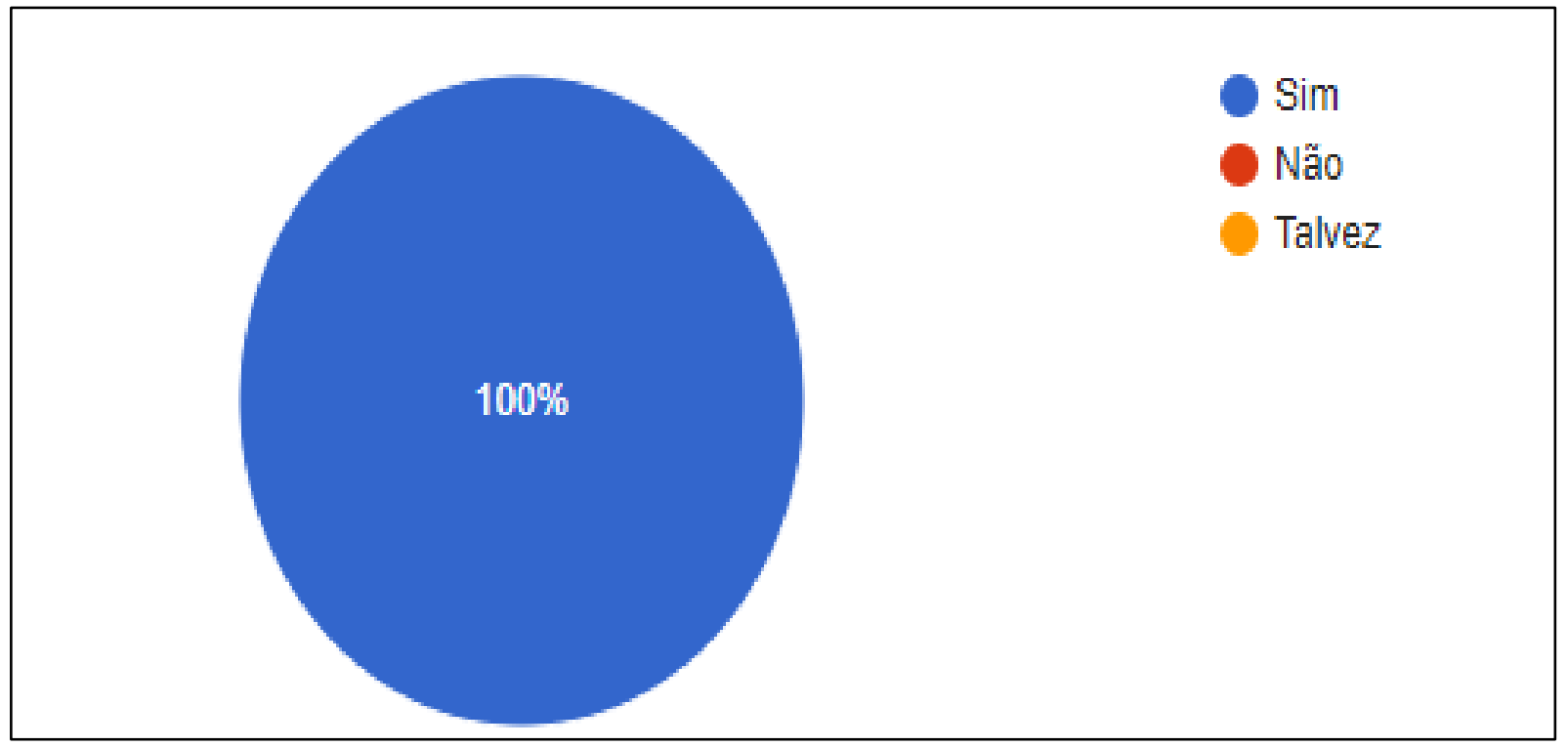


Gráfico 4: Você acredita que o livro tátil artesanal pode ser usado para qualquer disciplina

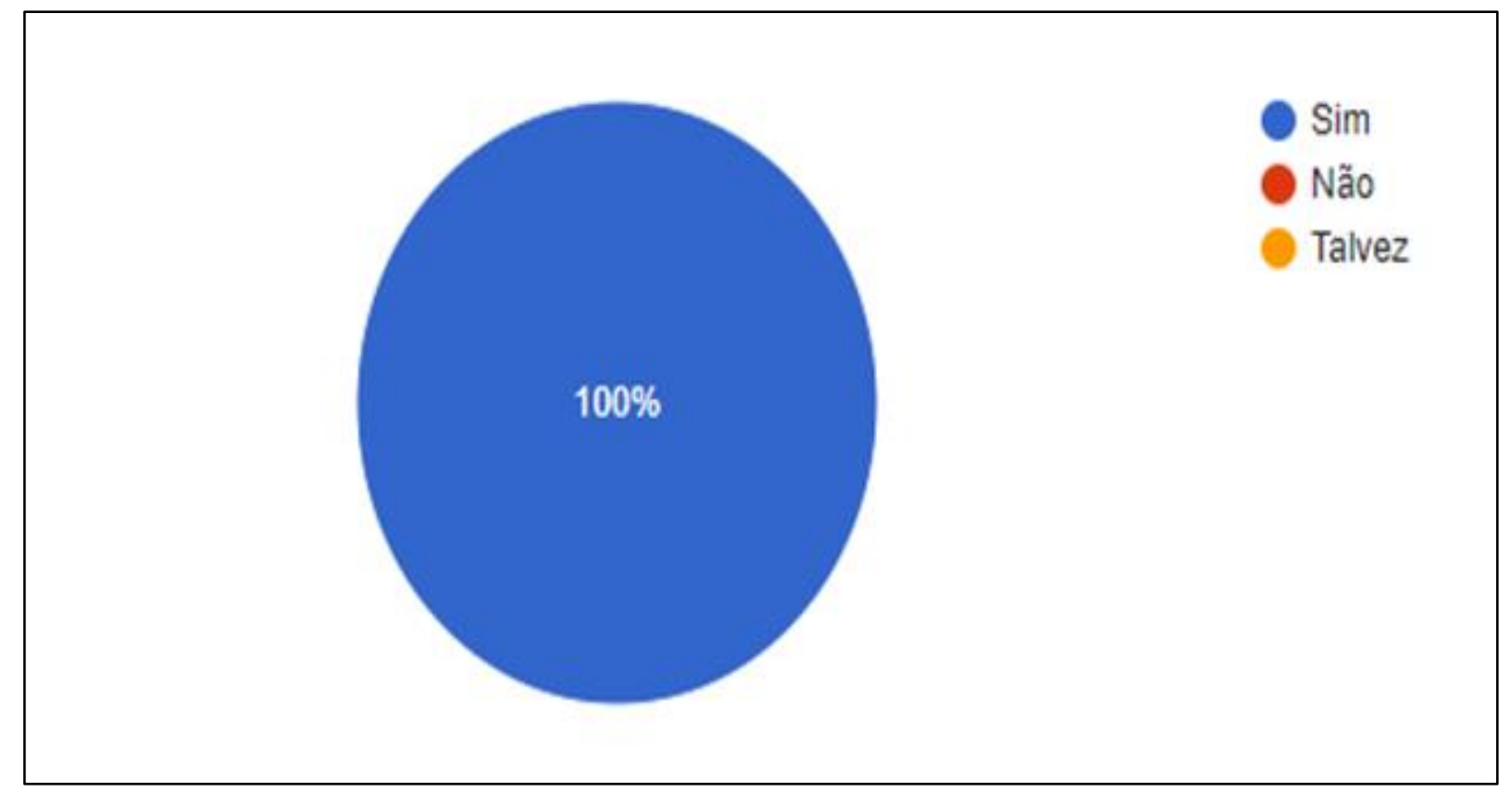

Gráfico 5: É possível trabalhar o lúdico com crianças DV no livro tátil

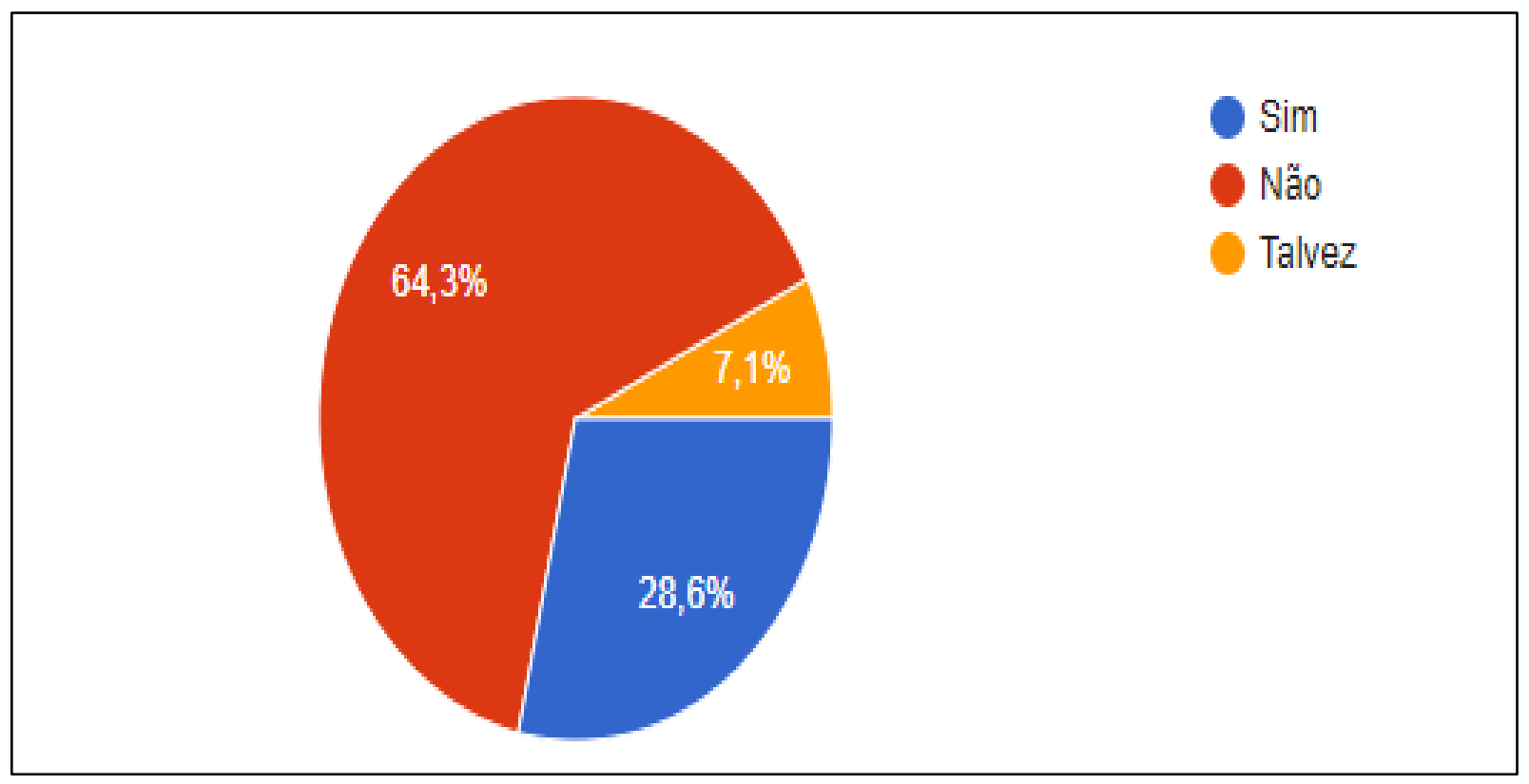

Gráfico 6: Na escola que você atua, há outros professores que compartilham desse recurso em sala de aula 


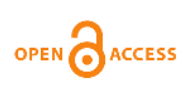

Desta forma, os dados dos gráficos mostraram resultados positivos do livro tátil artesanal que apresenta uma boa receptividade pelas cursistas e evidencia a sua importância como mais um recurso para complementar o aprendizado de uma pessoa com deficiência visual. A proposta do livro tátil é ser um livro inclusivo, onde as pessoas com deficiência visual tenham acesso as mesmas informações que uma criança vidente, por isso as ilustrações táteis têm que ser significativas e fidedignas as imagens visuais. De acordo com Tederixe ( 2019), os livros acessíveis, no contexto da deficiência visual, configuram todos os livros que viabilizam a informação visual de forma adaptada à necessidade da pessoa cega ou com baixa visão. "O material deve ter sua representação tão exata quanto possível do modelo original"(CERQUEIRA; FERREIRA, 200o, p. 26).

Com relação a ludicidade, o livro tem a função de trazer a informação ao seu leitor de forma clara e coerente para isso ele tem que ter uma boa legibilidade na leitura e atraente nas imagens, inclusive quando o livro é feito para crianças. Para Romani (20II), os instrumentos lúdicos nos livros infantis incentivam o interesse da criança ao propiciar emoções, estimular os sentidos e concentrar a energia da criança na manipulação do objeto, assim auxiliando no seu desenvolvimento. Os resultados do gráfico da figura 6 apontam que o livro tátil ainda é um recurso desconhecido e não muito utilizado nas escolas, principalmente, nas escolas inclusivas.

Os três próximos gráficos representam o desempenho de satisfação da metodologia abordada durante a oficina foi o Google sala de aula para interação assíncrona com os cursistas, o Google Meet para interações síncronas na eficácia do formato do ensino remoto como meio de capacitação profissional. Ressaltamos que a oficina de livro tátil, no qual requer a necessidade de um manuseio tátil do material para a experimentação das texturas e compreensão das ilustrações táteis, foi realizada com a demonstração visual do livro. Como também, a descrição das imagens, já que tivemos uma aluna cega. Certamente, esse foi o grande desafio de fazer uma oficina nesse formato, visto a necessidade de além de passar a informação e ter um cunho prático, também ser inclusiva. 
De forma geral, os gráficos mostram que "a oficina experimental” se mostrou relevante para este momento pandêmico para as cursistas.

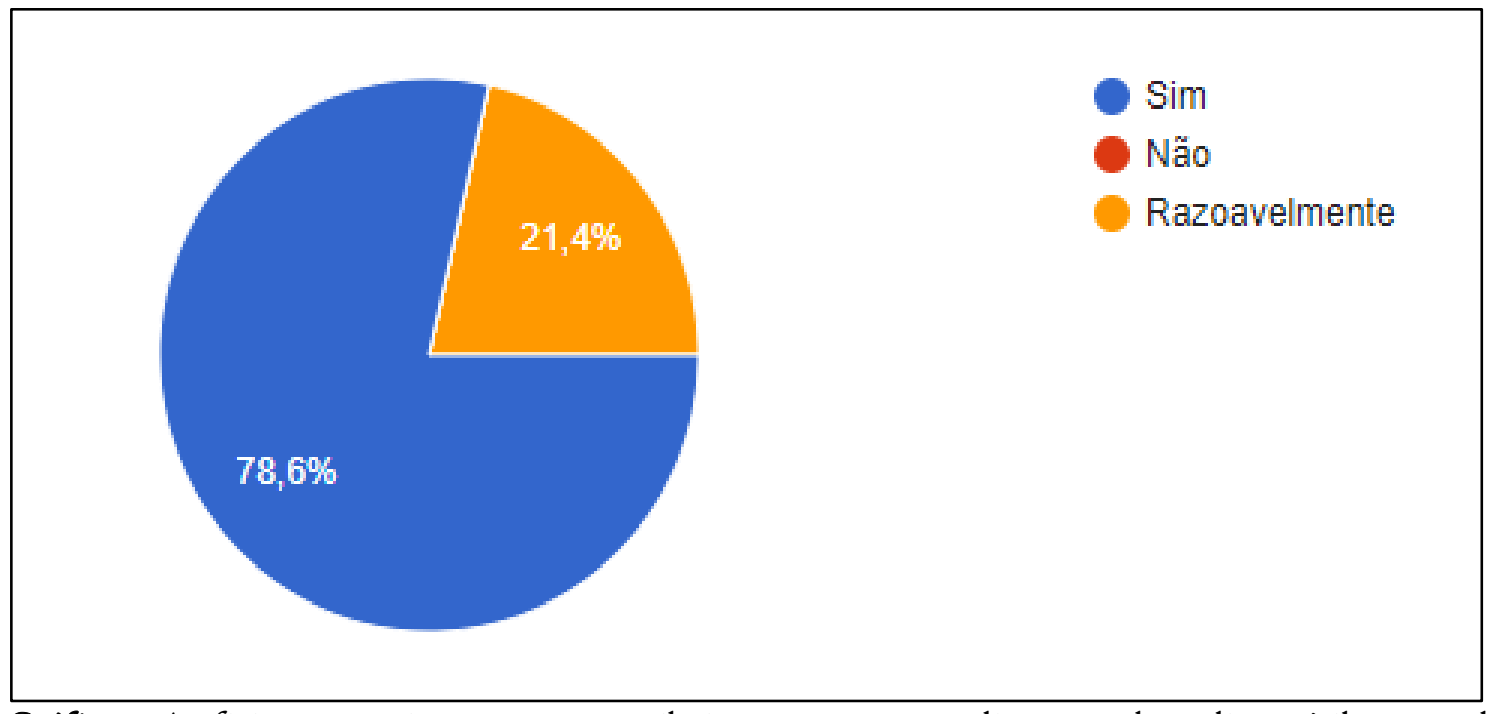

Gráfico 7: A oficina, no ensino remoto, contribuiu para o seu entendimento sobre o livro tátil artesanal

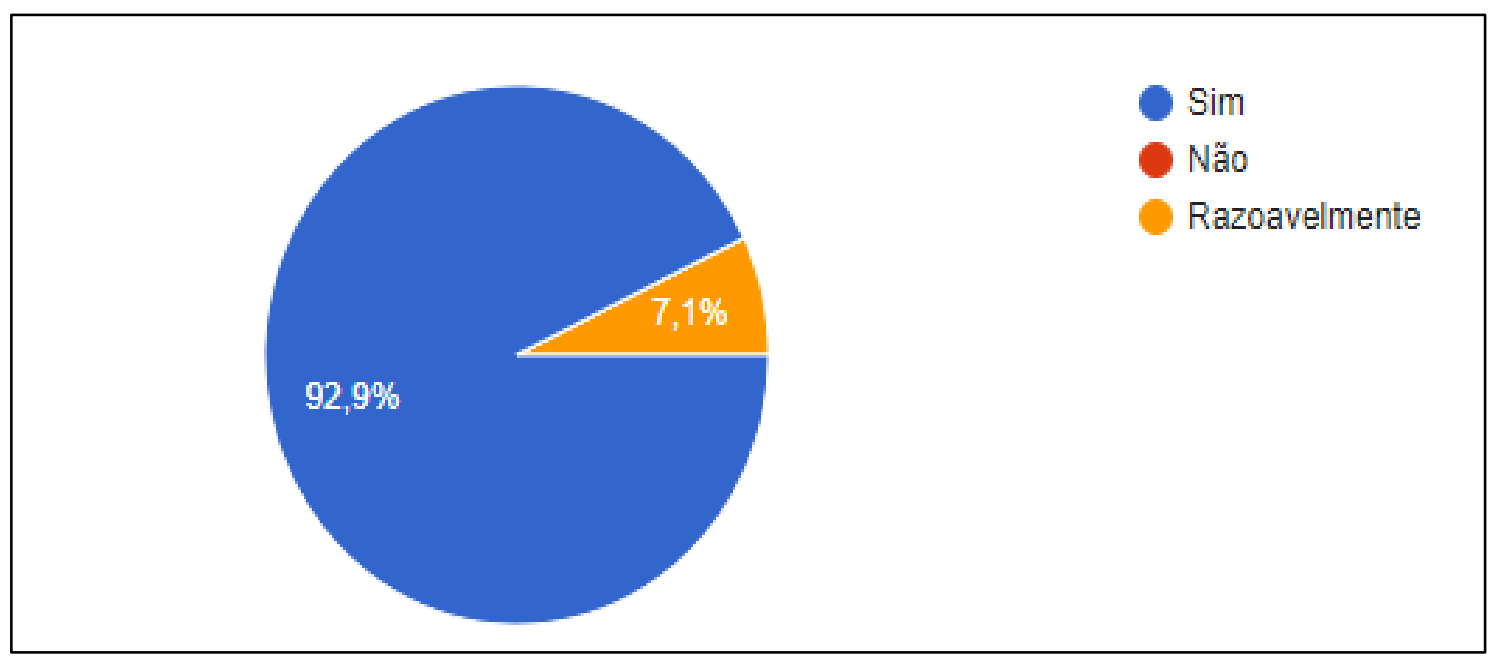

Gráfico 8: Os temas apresentados foram do interesse do cursista 


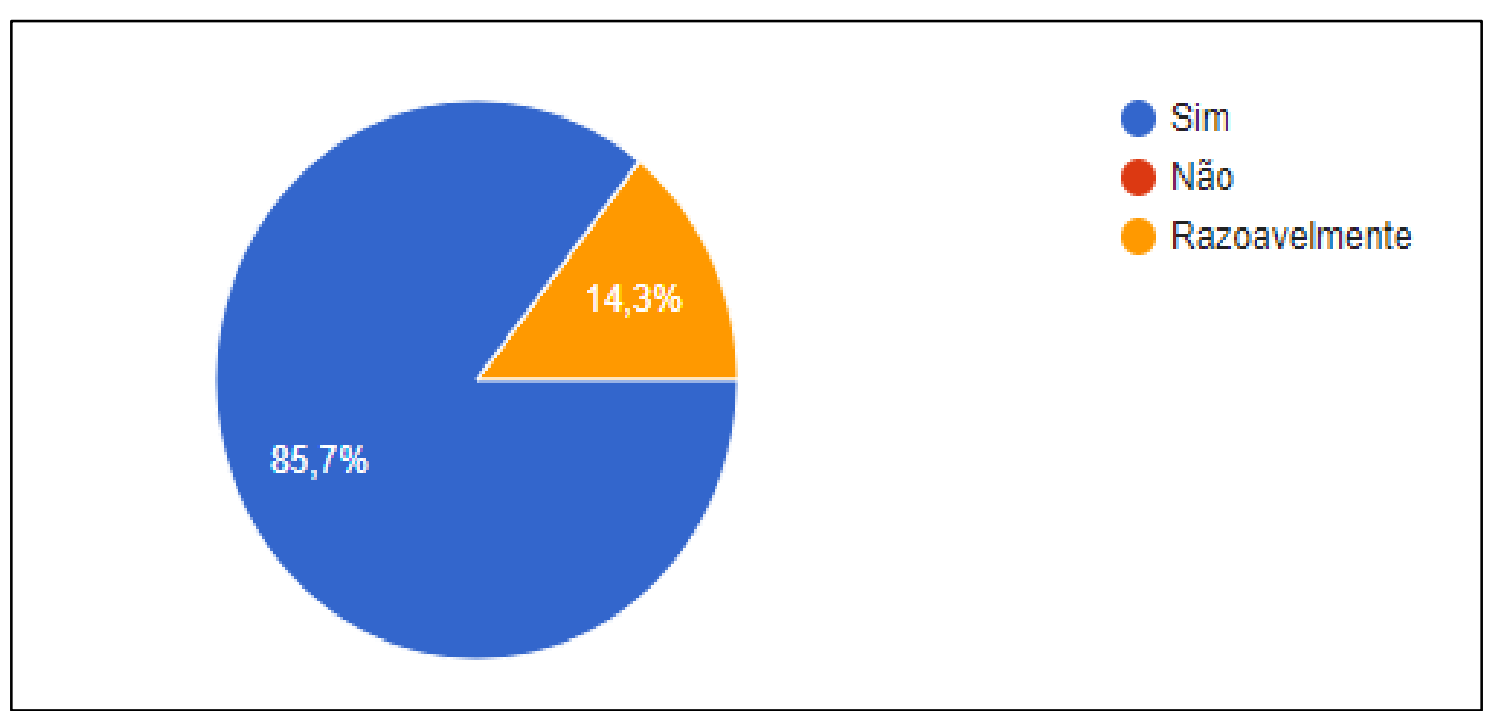

Gráfico 9: O material complementar fornecido foi relevante para o aprendizado do cursista

Também quisemos saber das cursistas, quais foram as dificuldades que elas tiveram em confeccionar um livro tátil artesanal. Selecionamos algumas respostas, pois há respostas que se repetem em virtude da própria situação de pandemia ou por outras razões de outras naturezas. "A dificuldade encontrada foi em relação ao Braille devido à falta de ferramentas nesse período de pandemia". "Sintetizar o texto / roteiro do livro para que o Braille não ficasse muito extenso." "Não senti dificuldade. Temos que ter paciência e criatividade." "Mas no momento o que dificultou mesmo foi só a questão da pandemia para está adquirindo os materiais, pelo fato de ter um pouco de habilidade manuais, acredito que não irei encontrar muitas dificuldades. Os materiais recicláveis também são ótimos recursos e acessíveis." Para a confecção do livro algumas orientações foram apresentadas as cursistas durante a oficina, como: a utilização de materiais recicláveis e a compra de materiais de baixo custo em lojas on-line que promovem frete grátis no primeiro acesso ao site. Segundo Lopes e Nunes (2010), a reutilização de materiais para a criação de modelos de estudos recicláveis ajuda no ensino e na didática dos alunos na sala de aula.

No questionário também foi pedido as participantes que dissessem em UMA palavra a contribuição da oficina para a sua prática em sala de aula. Selecionamos as palavras que tiveram mais destaque. As palavras "Criatividade" e "Inclusão" apareceram com mais frequência. "Para que um produto criativo seja gerado, conhecimento e técnica não são suficientes. É necessário que o indivíduo desenvolva, também, habilidades associadas à criatividade, tais como flexibilidade, originalidade, sensibilidade a problemas e imaginação [...]” (ALENCAR; FLEITH, 2003, p. 48).

O último dia da oficina foi o momento para que as cursistas tirassem as dúvidas e apresentassem parte de um livro tátil ou um protótipo/ planejamento que abordassem as técnicas de produção de um livro tátil artesanal. Algumas cursistas já trabalham com 
Educação Especial e em salas de recursos. Com isso, elas já atendem alunos com deficiência visual, auditivos e outras deficiências. Muitas dessas cursistas também estavam em trabalho remoto e precisavam elaborar materiais para enviar aos seus educandos e viram no livro um recurso para ensinar novos conceitos.

\section{CONSIDERAÇÕES FINAIS}

Para atender as demandas da educação na formação continuada de profissionais da educação, em tempos de pandemia, o formato de ensino remoto possibilitou a oferta e a criação da oficina de livro tátil na área de deficiência visual como meio de capacitação dessas cursistas, que mesmo em um período conturbado existem ferramentas digitais que estão a nossa disposição para a promoção de novos conhecimentos e assim melhorar o nosso atendimento ao alunado.

Ainda não há um mercado editorial específico para a criação de livros táteis e nem mesmo a disponibilidade de adaptação de imagens visuais em táteis para atender as necessidades das pessoas com deficiência visual, muitos desses materiais ainda são realizados de forma artesanal por profissionais que estão integrados a dar suporte na complementação didática desse público. Em virtude disso, trouxemos essa temática na configuração de oficina com o intuito de contribuir na formação continuada desses profissionais e trazer novos recursos no ensino da criança com deficiência visual. É preciso salientar o quanto é importante a produção desses recursos como o livro tátil artesanal para uma melhor qualificação no aprendizado dessa criança DV quanto a compreensão do conteúdo imagético em tátil.

Com base nos resultados da pesquisa realizada com as cursistas, entendemos que a oficina de uma forma geral se apresentou bem positiva e concluímos que a oficina, mesmo com uma dinâmica a distância, oportunizou um estudo sobre a questão da deficiência visual e a criação de narrativas infantis com ilustrações tátil e os métodos de produção do livro (objeto) para atender os pequenos leitores com DV.

\section{REFERÊNCIAS BIBLIOGRÁFICAS}

ALENCAR, Eunice Maria Lima Soriano de; FLEITH, Denise de Souza. Criatividade: múltiplas perspectivas. $3^{\underline{a}}$ ed. Brasília: Editora UNB. 2003. 129p.

ARIDE, Aline de Souza. Design Inclusivo: livro ilustrado multissensorial para crianças deficientes visuais e videntes. II2 fl. Trabalho de conclusão de curso (graduação) Universidade Federal do Rio de Janeiro, Curso de Comunicação Visual Design. UFRJ, Rio de Janeiro, 2015.

CERQUEIRA, Jonir Bechara; FERREIRA, Elise de Melo Borba. Recursos didáticos na educação especial. Benjamin Constant, Rio de Janeiro, RJ, no 15, p. 24-28. abr./jul. 6 - 2000. 
Disponível em: http://200.156.28.7/Nucleus/media/common/Nossos_Meios_RBC_Rev. Abr/ 2000_ARTIGO3.RTF. Acesso em: I2 de julho de 2021.

GARCIA, Tânia Cristina Meira et al. Ensino remoto emergencial: proposta de design para organização de aulas. Secretaria de educação a distância- UFRN, Cadernos de ensino mediado por TIC. I8 p, 2020. https://repositorio.ufrn.br/handle/123456789/29767. Acesso em: 22 de julho de 202I.

INSTITUTO BENJAMIN CONSTANT. Disponível em: http://ead.ibc.gov.br/. Acesso em: 22 de julho de 202I.

HODGES, Charles et al. A diferença entre ensino remoto emergencial e ensino a distância. Revista de la Red Iberoamericana de terminologia. $\mathrm{n}^{\circ} \mathrm{I} 8, \mathrm{p}$ 92-100, 2020 . Disponível em: https://seer.ufrgs.br/riterm/article/view/ı09402. Trad. Nathália Marcon, Rozane R. Rebechi. Acesso em: I2 de julho de 2021.

LOPES, Flavio Marques; NUNES, Andréia Neves. Reutilização de materiais recicláveis para incentivo à educação ambiental e auxílio ao ensino didático em ciências em um colégio estadual de Anápolis- GO. Revista de Educação. Vol. 13, n 15, p. 87-103, 2010. https://seer.pgsskroton.com/educ/issue/view/I86. Acesso em: I2 de julho de 202I.

PICCARDI, Francesca. I libri tattili illustrati nel processo di educazione all'immagine Del bambino con deficit visivo. , In: "Tiflologia per l'integrazione", n. I, 20II, Monza, Biblioteca Italiana per i Ciechi. Disponível em: http://libritattili.prociechi.it/approfondimenti/II73/ Acesso em: 20 julho de 202I.

.MEC. Resolução CNE/CP no $\mathbf{~}$, de 27 de outubro de 2020. Dispõe sobre as Diretrizes Curriculares Nacionais para a Formação Continuada de Professores da Educação Básica e institui a Base Nacional Comum para a Formação Continuada de Professores da Educação Básica(BNC-Formação Continuada). Disponível em: http://portal.mec.gov.br/docman/outubro-2020-pdf/r6484I-rcpoor-20/file. Acesso em: I2 de julho de 202I.

NUERNBERG, Adriano Henrique. Ilustrações táteis bidimensionais em livros infantis: considerações acerca de sua construção no contexto da educação de crianças com deficiência visual. In: Revista Educação Especial, Santa Maria, v. 23, n. 36, p. I3I-I44, jan./abr. 2010.

ROMANI, Elizabeth. Design do livro-objeto infantil. São Paulo, 20II, I44fl. (Dissertação de mestrado em Design e Arquitetura). FAUUSP. 201I. Disponível em: https://teses.usp.br/teses/disponiveis/r6/r6134/tde-IIo12012-II5004/publico /DISSERTACAO_DESIGN_DO_LIVRO_OBJETO.pdf. Acesso em: I2 de julho de 2021. 
ROMANI, Elizabeth. Design do livro tátil ilustrado: processo de criação centrado no leitor com deficiência visual e nas técnicas de produção gráfica da imagem e do texto. São Paulo.246p. Tese (Doutorado- Área de concentração :design e arquitetura) FAUUSP.2016.

SOUZA, Cristina Silva Ribeiro de. Livro Tátil Tridimensional de Itinerância Domiciliar para Ensino de Crianças cegas: Um caminho Lúdico na Promoção da Saúde. 2019. 74fl. Dissertação (Curso de Mestrado Profissional em Diversidade e Inclusão). Universidade Federal Fluminense, Niterói- RJ, 2019.

TEDERIXE, Lisânia Cardoso. Livro tátil: possibilidades de ensino e aprendizado da criança cega. 2019. 83 fl. Dissertação (Curso de Mestrado Profissional em Diversidade e Inclusão). Universidade Federal Fluminense, Niterói- RJ, 2019.

TEDERIXE, Lisânia Cardoso; LIMA, Neuza Rejane Wille. Técnicas de impressão de livros táteis para ledores com deficiência visual. In: LIMA, Neuza Rejane Wille; PERDIGÃO, Luciana Tavares; DELOU, Cristina Maria Carvalho (Organizadoras). Pontos de vista em diversidade e inclusão - volume 5. Niterói-RJ. Editora: Pensi. 2018. Pg75 a 8I.

TEDERIXE, Lisânia Cardoso; LIMA, Neuza Rejane Wille. Motivações para a produção de materiais didáticos de baixo custo para estudantes com deficiência visual . BrazilianJournalofPolicyandDevelopment, v. 2, n. 4, p. 184-216, 30 dez. 2020. 